\title{
Angiogenin and vascular endothelial growth factor expression in lungs of lung cancer patients
}

\author{
Ales Rozman ${ }^{1,3}$, Mira Silar², Mitja Kosnik³ \\ ${ }^{1}$ Department for Endoscopy, ${ }^{2}$ Department for Immunology, ${ }^{3}$ Department for Pulmonology, University Clinic Golnik, Slovenia \\ Radiol Oncol 2012; 46(4): 354-359. \\ Received 20 January 2012 \\ Accepted 21 February 2012 \\ Correspondence to: Aleš Rozman, MD, MSc, Department for Endoscopy and Department for Pulmonology, University Clinic Golnik, Golnik 36, \\ 4204 Golnik, Slovenia. Phone: +386 41313 811; Fax: +386 4256 9117; E-mail: ales.rozman@klinika-golnik.si \\ Disclosure: No potential conflicts of interest were disclosed.
}

Background. Lung cancer is the leading cause of cancer deaths. Angiogenesis is crucial process in cancer growth and progression. This prospective study evaluated expression of two central regulatory molecules: angiogenin and vascular endothelial growth factor (VEGF) in patients with lung cancer.

Patients and methods. Clinical data, blood samples and broncho-alveolar lavage (BAL) from 23 patients with primary lung carcinoma were collected. BAL fluid was taken from part of the lung with malignancy, and from corresponding healthy side of the lung. VEGF and angiogenin concentrations were analysed by an enzyme-linked immunosorbent assay. Dilution of bronchial secretions in the BAL fluid was calculated from urea concentration ratio between serum and BAL fluid.

Results. We found no statistical correlation between angiogenin concentrations in serum and in bronchial secretions from both parts of the lung. VEGF concentrations were greater in bronchial secretions in the affected side of the lung than on healthy side. Both concentrations were greater than serum VEGF concentration. VEGF concentration in serum was in positive correlation with tumour size $(p=0,003)$ and with metastatic stage of disease $(p=0,041)$. There was correlation between VEGF and angiogenin concentrations in bronchial secretions from healthy side of the lung and between VEGF and angiogenin concentrations in bronchial secretions from part of the lung with malignancy.

Conclusion. Angiogenin and VEGF concentrations in systemic, background and local samples of patients with lung cancer are affected by different mechanisms. Pro-angiogenic activity of lung cancer has an important influence on the levels of angiogenin and VEGF.

Key words: angiogenin; BAL fluid; bronchoscopy; lung cancer; vascular endothelial growth factor

\section{Introduction}

Lung cancer is one of the leading causes of morbidity and cancer-related mortality in Slovenia with 1216 new cases and 1125 deaths in 2007. ${ }^{1}$ Five-year survival rate is around $10 \%$, since most of the patients have advanced stage of disease at the time of diagnosis. ${ }^{2,3}$ Tumour growth and progression is still poorly understood and in many cases doesn't follow currently accepted model of sequential multistep pathway. ${ }^{4-7}$

Beside transformation of normal cells into malignant, the cancer growth and progression re- quires additional steps to transition from dormant to malignant state. ${ }^{8,9}$ The role of angiogenesis - the growth of new vessels from preexisting - is probably fundamental in this process. ${ }^{10,11}$ Angiogenesis is controlled by a delicate balance between pro- and anti-angiogenic factors which is disrupted by a malignant tumour in favour of forming its own blood vessel network. ${ }^{12,13}$ Moreover, angiogenesis is involved also in the growth of distant metastases. ${ }^{14}$

The central roles in the process of neovascularisation have regulatory molecules with pro- and anti-angiogenic potential. ${ }^{15}$ Vascular endothelial growth factor (VEGF) and angiogenin are two ma- 
TABLE 1. Clinical and demographic characteristics of the lung cancer patients from the study

\begin{tabular}{|c|c|}
\hline Variables & Data \\
\hline No. of patients & 23 \\
\hline Median age, years & 66 (range 48-78) \\
\hline Male, $n(\%)$ & $22(95.7 \%)$ \\
\hline Female, $n(\%)$ & $1(4.3 \%)$ \\
\hline \multicolumn{2}{|l|}{ Smoking status, $n$ (\%) } \\
\hline Current and previous & $22(95.7 \%)$ \\
\hline Never-smoker & $1(4.3 \%)$ \\
\hline COPD, n (\%) & $14(60.9 \%)$ \\
\hline \multicolumn{2}{|l|}{ Cancer type } \\
\hline Squamous cell carcinoma & $13(56.6 \%)$ \\
\hline Small cell carcinoma & $5(21.7 \%)$ \\
\hline Adenocarcinoma & $3(13.0 \%)$ \\
\hline Others & $2(8.7 \%)$ \\
\hline \multicolumn{2}{|l|}{ Stage, $n$ (\%) } \\
\hline I & $4(17.4 \%)$ \\
\hline$\|$ & $1(4.3 \%)$ \\
\hline III & $8(34.8 \%)$ \\
\hline IV & $10(43.5 \%)$ \\
\hline Tumour size, $\mathrm{cm}$ & $5.7 \pm 3.0$ \\
\hline \multicolumn{2}{|l|}{ Location, n (\%) } \\
\hline central & $16(69.6 \%)$ \\
\hline peripheral & $7(30.4 \%)$ \\
\hline CRP, mg/l & $36.5 \pm 32.8$ \\
\hline WBC, $\times 10^{6} / 1$ & $11.1 \pm 9.6$ \\
\hline
\end{tabular}

COPD = chronic obstructive lung disease; $C R P=C$-reactive protein; $W B C$ $=$ white blood count

jor positive regulators of blood vessel formation in physiological conditions and in pathological situations including lung cancer. ${ }^{16-20}$

The purpose of this study was to prospectively investigate the local concentrations of VEGF and angiogenin in the part of the lung, affected by a lung cancer and compare them by the healthy side of the lung and by the concentrations in the serum of patients with lung cancer.

\section{Patients and methods}

\section{Patients}

Thirty patients who underwent bronchoscopy with suspicion for lung malignancy were included. Exclusion criteria were: age under 18 years, malig- nancy on both sides of the lung or additional malignoma elsewhere in the body, previous anticancer treatment or pneumonectomy. The procedure was explained to patients verbally and in writing, and signed informed consent was obtained prior to enrolment. The study was approved by the National Medical Ethics Committee. We subsequently excluded 7 patients where lung malignancy was not confirmed by invasive diagnostic procedures. Clinical and demographic characteristics of the included lung cancer patients are presented in Table 1. Ex-smokers were defined as former regular smokers, who stopped at least one year before enrolment.

\section{Broncho-alveolar lavage (BAL) and blood samples}

Venous blood samples were collected before bronchoscopy into a vacutainer without anticoagulant or other additives. Serum was separated and centrifuged at 2500 revolutions per minute for $5 \mathrm{~min}$ utes, and supernatant was frozen at $-40^{\circ} \mathrm{C}$. During bronchoscopy BAL with $20 \mathrm{ml}$ of saline was collected from segmental bronchus affected by lung cancer and from corresponding segmental bronchus on the healthy side of the lung. BAL was performed before biopsies, from the healthy side first to avoid contamination with blood and malignant cells. BAL fluid was centrifuged at 1600 revolutions per minute for 5 minutes after procedure and supernatant was frozen at $-40^{\circ} \mathrm{C}$ for later analysis.

\section{VEGF, angiogenin and urea measurement}

Enzyme-linked immunosorbent assay (ELISA) kits (Quantikine - R\&D Systems, Minneapolis) were used for measurements of VEGF and angiogenin in plasma and BAL fluid. The limit of sensitivity of the VEGF assay was 5-9 pg/ml, the intra-assay coefficient of variation was $4.1-6.7 \%$ and the interassay coefficient of variation was $5.0-8.8 \%$. The limit of sensitivity of the angiogenin assay was $6 \mathrm{pg} / \mathrm{ml}$, the intra-assay coefficient of variation was $2.8-3.3 \%$ and the interassay coefficient of variation was 7.1 $-8.7 \%$. Urea concentration in plasma and BAL fluid was measured by QuantiChrom urea assay kit Diur-500 (BioAssay Systems, Hayward) with linear detection range from $0.06 \mathrm{mg} / 1$ to $1000 \mathrm{mg} / \mathrm{l}$.

\section{Data analysis}

Concentrations of angiogenin and VEGF in bronchial samples were normalized to urea concentra- 
TABLE 2. Concentrations of angiogenin in serum and in bronchial secretions from healthy side of the lung and from area, affected by lung cancer

\begin{tabular}{|c|c|c|c|c|}
\hline Serum (ng/ml) & 286.94 & 267.88 & 397.08 & 495.88 \\
\hline Bronchial secretions - lung cancer (ng/ml) & 306.11 & 221.19 & 592.69 & 12591.24 \\
\hline
\end{tabular}

Me = median, $Q 1=$ first quartile, $Q 3=$ third quartile

TABLE 3. Concentrations of VEGF in serum and in bronchial secretions from healthy side of the lung and from area, affected by lung cancer. There was a significant difference between serum and bronchial concentrations $(p<0.05)$, but no significant difference among VEGF concentrations between diseased and healthy side of the lung ( $p>0.05)$

\begin{tabular}{lllcc}
\hline VEGF concentration & Me & Q1 & Q3 & 95.centil \\
\hline Serum $(\mathrm{ng} / \mathrm{ml})$ & 0.74 & 0.48 & 1.27 & 3.79 \\
Bronchial secretions - healthy side $(\mathrm{ng} / \mathrm{ml})$ & 14.52 & 8.59 & 26.59 & 111.05 \\
Bronchial secretions - lung cancer $(\mathrm{ng} / \mathrm{ml})$ & 17.89 & 8.64 & 84.30 & 565.49 \\
\hline
\end{tabular}

Me - median, Q1 - first quartile, Q3 - third quartile

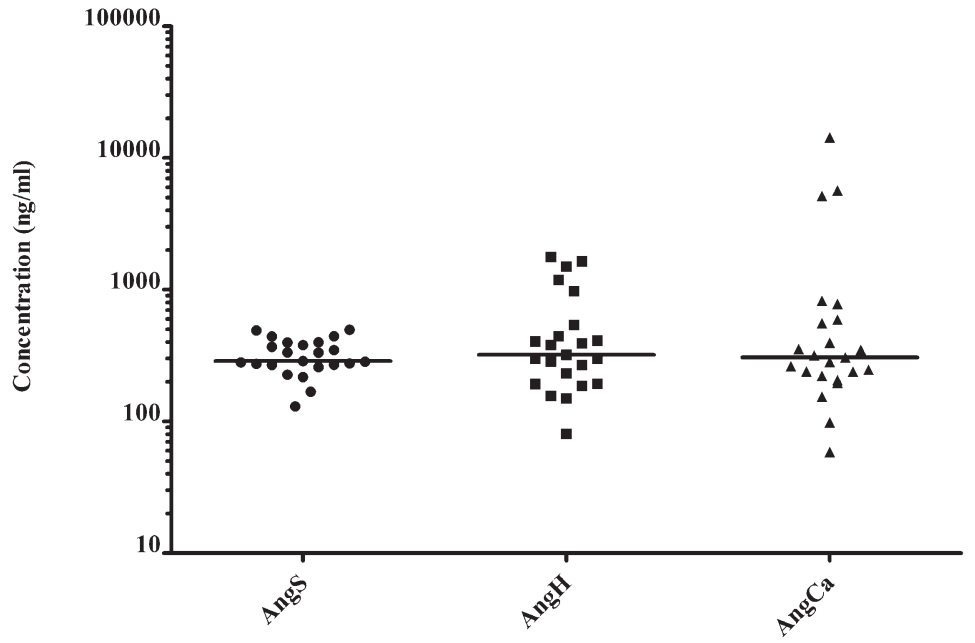

FIGURE 1. Distributions of angiogenin concentrations in serum (AngS), bronchial secretions from healthy side of the lung $(\mathrm{AngH})$ and from area, affected by lung cancer (AngCa). tion. Concentrations of VEGF and angiogenin in bronchial secretions were calculated using formula: bronchial secretions concentration $=$ BAL fluid concentration $\mathrm{x}$ (urea concentration in plasma / urea concentration in BAL fluid).

Data were analysed using the computer program Statistical Package for the Social Sciences version 14.0 (SPSS Inc., Chicago). Descriptive statistical methods were used (mean, standard deviation, range / median, percentiles). A Kolmogorov-
Smirnov (KS) test was used to check normal distribution. Associations between variables were tested by Pearson non-parametric test and by Wilcoxon matched-pairs test. Differences were analysed by Mann-Whitney U test. All tests were two-tailed; $p$ $<0.05$ was considered to be statistical significant.

\section{Results}

Median dilution of bronchial secretions in BAL fluid was 1:104 on the healthy side of the lung and 1:97 in the area of the lung affected by lung cancer, according to differences in urea concentrations.

Only serum concentrations of angiogenin followed Gaussian distribution ( $K S=0.16, \mathrm{p}>0.05$ ).

Median angiogenin serum concentration in patients with lung cancer was $286.94 \mathrm{ng} / \mathrm{ml}$ (Table 2). We found no significant correlation among angiogenin concentrations in serum and bronchial secretions of both sides of the lung $(p>0.05)$. No significant difference was found among angiogenin concentrations in serum and bronchial secretions of both sides of the lung $(p>0.05)$ (Figure 1$)$.

VEGF concentrations in bronchial secretions were higher than in the serum of patients with lung cancer (Table 3). VEGF concentrations in the bronchial secretions from lung cancer area show no statistical difference to VEGF concentrations in bronchial secretions from the healthy side of 
the lung (Figure 2). There was no significant correlation among VEGF concentrations in serum and bronchial secretions found ( $p>0.05)$.

Concentrations of angiogenin and VEGF in bronchial secretions from the healthy side of the lung were in a correlation $(p=0.003)$ as well as angiogenin and VEGF concentrations from area affected with lung cancer $(\mathrm{p}<0.001)$. Angiogenin and VEGF concentrations in the serum did not correlate.

Concentrations of serum VEGF were in a positive correlation with tumour size $(\mathrm{p}=0.003)$, plasma C-reactive protein $(C R P)$ concentrations $(p=0.007)$, white blood count (WBC) in peripheral blood sample $(\mathrm{p}<0.001)$ and metastatic stage of disease $(\mathrm{p}=$ 0.041). Serum angiogenin concentrations were not in a correlation with any of tumour features or inflammatory markers.

\section{Discussion}

The study showed that there is a strong local production of VEGF in lungs of patients with lung cancer and that VEGF serum concentration but not angiogenin concentration was in positive correlation with tumour size and with metastatic stage of disease. Concentrations of VEGF and angiogenin did not correlate for a particular molecule in any possible couple from three taken samples in patients with lung cancer. This is probably a consequence of different mechanisms, which regulate concentrations of these two molecules in any of these three settings.

Serum as a systemic sample has certain levels of VEGF and angiogenin present also in subjects without malignant disease and their concentration is therefore dependant on mechanisms other than malignancy, such are inflammation, hypoxemia, injury and tissue repair and maintenance..$^{21,22}$

Angiogenin is normally present in the serum of healthy people and is produced in many tissues, among other in the liver as a constituent of acute phase response. ${ }^{23,24}$ Its concentrations are higher in heart failure, abnormal pregnancy, blood malignancies and in some other conditions. ${ }^{25,26}$ Higher expression of angiogenin was found in bronchial mucosa of asthmatics, especially during periods of exacerbation. ${ }^{27,28}$ In this study serum angiogenin concentrations followed Gaussian distribution in contrast to angiogenin concentrations in bronchial secretions from both sides of the lung. Therefore we assume that serum angiogenin concentration was not significantly affected by local conditions in the lung and in the lung cancer. Moreover serum

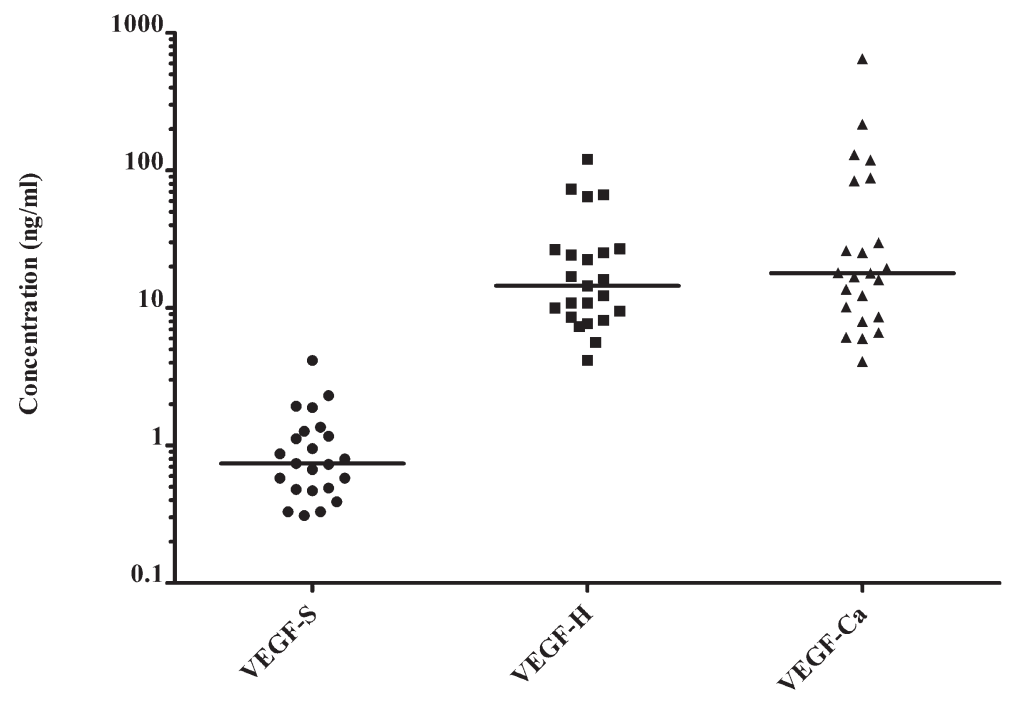

FIGURE 2. Distributions of VEGF concentrations in serum (VEGF-S), bronchial secretions from healthy side of the lung (VEGF-H) and from area, affected by lung cancer (VEGF-Ca).

angiogenin concentrations were not in correlation with any of the clinical variables as for example: CRP, WBC, tumour size, stage of the disease, chronic obstructive lung disease (COPD), etc.

In contrast, VEGF concentrations in the serum were much lower than in the samples from the lung, and were not in correlation with lung concentrations. Serum VEGF concentrations were strongly correlated with some clinical variables: CRP, WBC, tumour size and stage of the disease. This is in accordance with previously described higher serum VEGF expression in patients with advanced disease. ${ }^{29,30}$ Serum concentrations of VEGF are normally very low and are probably the result of "washing" from tissues, where VEGF expression is higher. ${ }^{31,32}$

The measurements of exact concentrations of angiogenin and VEGF in bronchial secretions represented a certain challenge, since dilution rate of bronchial secretions in BAL was different from sample to sample. Angiogenin and VEGF concentrations in BAL fluid were dependant on their concentrations in bronchial secretions and on the amount of bronchial secretions captured in the retrieved BAL fluid. For defining of exact dilution rate of secretions in the BAL we used concentrations of urea molecules and two compartment model method. Urea freely diffuses between plasma and bronchial secretions and its concentration in both fluids is equal, since urea is neither degraded or produced in bronchi nor is volatile. $33-35$

Bronchial secretions from the healthy side of the lung were regarded as a "lung background" 
sample. Correlation between angiogenin and VEGF concentrations in bronchial secretions from the healthy side of the lung is probably the consequence of the same stimulus. Bronchial inflammation in asthma and COPD can stimulate secretion of angiogenin and VEGF. ${ }^{27,28}$ VEGF concentrations in bronchial secretions can rise even in asymptomatic smokers. ${ }^{36}$ Almost all of the patients in this study were current or former smokers and $60.9 \%$ had diagnosis of COPD that could contribute especially to higher VEGF concentrations.

Bronchial secretions from the area of the lung, affected with lung cancer were "local" sample. Concentrations of angiogenin and VEGF were in correlation and we again assume that stimulus for secretion could be the same. VEGF concentrations were higher in bronchial washings from patients with lung cancer after treatment with chemotherapy and irradiation, but none of included patients in this study received such treatment before. ${ }^{37}$ VEGF concentrations in bronchial secretions from affected side of the lung were not in correlation with any of the tumour features, what possibly reflects the effect of VEGF "washing" to the blood serum, which in contrast reflects such correlations. We were unable to confirm the findings that VEGF expression in the airways is inversely associated with tumour progression. ${ }^{38}$

Limitations of the study were small number of included patients, and inhomogenity of the study group. Small sample size prevented subgroup analysis. In the study group were differences in gender and histological types of lung cancer with regard to general distribution in population of patients with lung cancer.

We summarize that angiogenin and VEGF expression in systemic, background and local samples of patients with lung cancer are affected by different mechanisms. The important role in serum angiogenin concentration has constitutional component in contrast to serum VEGF concentration, which is influenced by lung cancer. Angiogenin and VEGF concentrations in bronchial secretions from healthy and affected side of the lung show influence of lung cancer angiogenic activity and other conditions including co-morbidity.

\section{Acknowledgements}

The authors would like to thank to Nadja Triller and to Viljem Kovač for support during clinical trial and preparation of the manuscript.

\section{References}

1. Cancer in Slovenia 2007. Ljubljana: Institute of Oncology Ljubljana, Epidemiology and Cancer Registry, Cancer Registry of Republic of Slovenia; 2010.

2. Debevec L, Debeljak A, Eržen J, Kovač V, Kern I. Characterisation of lung cancer patients, their actual treatment and survival: experience in Slovenia. Radiol Oncol 2005; 39: 115-21.

3. Lekic M, Kovac V, Triller N, Knez L, Sadikov A, Cufer T. Outcome of small cell lung cancer (SCLC) patients with brain metastases in a routine clinical setting. Radiol Oncol 2012; 46: 54-9.

4. Bach PB. Is our natural - history model of lung cancer wrong? Lancet Oncol 2008; 9: 693-7.

5. Park IW, Wistuba II, Maitra A, Milchgrub S, Virmani AK, Minna JD, et al. Multiple clonal abnormalities in the bronchial epithelium of patients with lung cancer. J Nat/ Cancer Inst 1999; 91: 1863-8.

6. Venmans BJ, van Boxem TJ, Smit EF, Postmus PE, Sutedja G. Outcome of bronchial CIS. Chest 2000; 117: 1472-6.

7. Bach PB, Jett JR, Pastorino U, Tockman MS, Swensen SJ, Begg CB. Computed tomography screening and lung cancer outcomes. JAMA 2007; 297: 953-61.

8. Folkman J, Kalluri R. Cancer without disease. Nature 2004; 427: 787.

9. McFarlane MJ, Feinstein AR, Wells CK. Clinical features of lung cancers discovered as a postmortem "surprise". Chest 1986; 90: 520-3.

10. Naumov GN, Akslen LA, Folkman J. Role of angiogenesis in human tumo dormancy. Animal models of the angiogenic switch. Cell Cycle 2006; 5: 1779-87.

11. Hanahan D, Folkman J. Patterns and emerging mechanisms of the angiogenic switch during tumorogenesis. Cell 1996; 86: 353-64.

12. Kerbel RS. Tumor angiogenesis. N Engl J Med 2008; 358: 2039-49.

13. Ciric E, Sersa G. Radiotherapy in combination with vascular-targeted therapies. Radiol Oncol 2010; 44: 67-78.

14. Macchiarini P, Fontanini G, Dulmet E, de Montpreville V, Chapelier AR, Cerrina J, et al. Angiogenesis: an indicator of metastasis in non-small cell lung cancer invading the thoracic inlet. Ann Thorac Surg 1994; 57: 1534-9.

15. Distler JH, Hirth A, Kurowska-Stolarska M, Gay RE, Gay S, Distler O. Angiogenic and angiostatic factors in the molecular control of angiogenesis. Q J Nucl Med 2003; 47: 149-61.

16. Tello-Montoliu A, Patel JV, Lip GYH. Angiogenin: a review of the patophysiology and potential clinical applications. J Thromb Haemost 2006; 4: 1864-4.

17. Gao X, Xu Z. Mechanisms of action of angiogenin. Acta Biochim Biophys Sin 2008; 40: 619-24.

18. Ferrara N, Davis-Smyth T. The biology of vascular endothelial growth factor. Endocrine Rev 1997; 18: 4-25.

19. Veikkola T, Alitalo K. VEGFs, receptors and angiogenesis. Semin Cancer Biol 1999; 9: 211-20.

20. Shibuya M. Vascular endothelial growth factor - dependent and - independent regulation of angiogenesis. BMB reports 2008; 41: 278-86.

21. Shapiro R, Strydom DJ, Olson KA, Vallee BL. Isolation of angiogenin from normal human plasma. Biochemistry 1987; 26: 5141-6.

22. Wasada T, Kawahara R, Katsumori K, Naruse M, Omori Y. Plasma concentration of immunoreactive vascular endothelial growth factor and its relation to smoking. Metabolism 1998; 47: 27-30.

23. Olson KA, Verselis SJ, Fett JW. Angiogenin is regulated in vivo as an acute phase protein. Biochem Biophys Res Commun 1998; 242: 480-3.

24. Pantsulaia la, Trofimov S, Kobyliansky E, Livshits G. Genetic and environmental determinants of circulating levels of angiogenin in community-based sample. Clin Endocrino 2006; 64: 271-9.

25. Kolben M, Bläser J, Ulm K, Schmitt M, Schneider KT, Tschesche H, et al. Angiogenin plasma levels during pregnancy. Am J Obstet Gynecol 1997; 176: $37-41$. 
26. Patel JV, Sosin M, Gunarathne A, Hussain I, Davis RC, Hughes EA, et al. Elevated angiogenin levels in chronic heart failure. Ann Med 2008; 40: 474-9.

27. Hoshino M, Takahashi M, Aoike N. Expression of vascular endothelial growth factor, basic fibroblast growth factor, and angiogenin immunoreactivity in asthmatic airways and its relationship to angiogenesis. J Allergy Clin Immunol 2001; 107: 295-301.

28. Abdel-Rahman AMO, El-Sahrigy SAF, Bakr SI. A comparative study of two angiogenic factors: vascular endothelial growth factor and angiogenin in induced sputum from asthmatic children in acute attack. Chest 2006; 129: 266-71.

29. Matsuyama W, Hashiguchi T, Mizoguchi A, Iwami F, Kawabata M, Arimura K, et al. Serum levels of vascular endothelial growth factor dependent on the stage progression of lung cancer. Chest 2000; 118: 948-51.

30. Yuan A, Yu CJ, Chen WJ, Lin FY, Kuo SH, Luh KT et al. Correlation of total VEGF mRNA and protein expression with histologic type, tumor angiogenesis, patient survival and timing of relapse in non-small-cell lung cancer. Int Cancer 2000; 89: 475-83.

31. Berse B, Brown LF, Van de Water L, Dvorak HF, Senger DR. Vascular permeability factor (vascular endothelial growth factor) gene is expressed differentially in normal tissues, macrophages, and tumors. Mol Biol Cell 1992; 3: 211-20.

32. Mura M, dos Santos CC, Stewart D, Liu M. Vascular endothelial growth factor and related molecules in acute lung injury. J Appl Physiol 2004; 97: 1605-17.

33. Effros RM, Peterson B, Casaburi R, Su J, Dunning M, Torday J, et al. Epithelia lining fluid solute concentrations in chronic obstructive lung disease patients and normal subjects. J Appl Physiol 2005; 99: 1286-92.

34. Rennard SI, Basset G, Lecossier D, O'Donnell KM, Pinkston P, Martin PG, et al. Estimation of volume of epithelial lining fluid recovered by lavage using urea as marker for dilution. J Appl Physiol 1986; 60: 532-8.

35. Effros RM, Murphy $C$, Ozker $K$, Hacker A. Kinetics of urea exchange in air - filled and fluid - filled rat lungs. Am J Physiol Lung Cell Mol Physiol 1992; 263: L619-26.

36. Rovina N, Papapetropoulos A, Kollintza A, Michailidou M, Simoes DC Roussos $C$, et al. Vascular endothelial growth factor: an angiogenic factor reflecting airway inflammation in healthy smokers and in patients with bronchitis type of chronic obstructive pulmonary disease? Respir Res 2007; 8: 53

37. Beinert T, Binder D, Oehm C, Ziemer S, Priem F, Stuschke M, et al. Furthe evidence for oxidant-induced vascular endothelial growth factor up-regulation in the bronchoalveolar lavage fluid of lung cancer patients undergoing radio-chemotherapy. J Cancer Res Clin Oncol 2000; 126: 352-6.

38. Ohta Y, Ohta N, Tamura M, Wu J, Tsunezuka Y, Oda M, et al. Vascular endothelial growth factor expression in airways of patients with lung cancer A possible diagnostic tool of responsive angiogenic status on the host side. Chest 2002; 121: 1624-7. 